\title{
Early treatment versus expectative management of patent ductus arteriosus in preterm infants: a multicentre, randomised, non-inferiority trial in Europe (BeNeDuctus trial)
}

Tim Hundscheid ${ }^{1 *}$ (D), Wes Onland², Bart van Overmeire ${ }^{3}$, Peter Dijk ${ }^{4}$, Anton H. L. C. van Kaam ${ }^{5}$, Koen P. Dijkman ${ }^{6}$, Elisabeth M. W. Kooi ${ }^{4}$, Eduardo Villamor ${ }^{7}$, André A. Kroon ${ }^{8}$, Remco Visser ${ }^{9}$, Daniel C. Vijlbrief ${ }^{10}$, Susanne M. de Tollenaer ${ }^{11}$, Filip Cools ${ }^{12}$, David van Laere ${ }^{13}$, Anne-Britt Johansson ${ }^{14}$, Catheline Hocq ${ }^{15}$, Alexandra Zecic $^{16}$, Eddy Adang ${ }^{17}$, Rogier Donders ${ }^{17}$, Willem de Vries ${ }^{10}$, Arno F. J. van Heijst ${ }^{1}$ and Willem P. de Boode ${ }^{1}$

\begin{abstract}
Background: Much controversy exists about the optimal management of a patent ductus arteriosus (PDA) in preterm infants, especially in those born at a gestational age (GA) less than 28 weeks. No causal relationship has been proven between a (haemodynamically significant) PDA and neonatal complications related to pulmonary hyperperfusion and/or systemic hypoperfusion. Although studies show conflicting results, a common understanding is that medical or surgical treatment of a PDA does not seem to reduce the risk of major neonatal morbidities and mortality. As the PDA might have closed spontaneously, treated children are potentially exposed to iatrogenic adverse effects. A conservative approach is gaining interest worldwide, although convincing evidence to support its use is lacking.

Methods: This multicentre, randomised, non-inferiority trial is conducted in neonatal intensive care units. The study population consists of preterm infants (GA $<28$ weeks) with an echocardiographic-confirmed PDA with a transductal diameter $>1.5 \mathrm{~mm}$. Early treatment (between 24 and $72 \mathrm{~h}$ postnatal age) with the cyclooxygenase inhibitor (COXi) ibuprofen (IBU) is compared with an expectative management (no intervention intended to close a PDA). The primary outcome is the composite of mortality, and/or necrotising enterocolitis (NEC) Bell stage $\geq \| l a$, and/or bronchopulmonary dysplasia (BPD) defined as the need for supplemental oxygen, all at a postmenstrual age (PMA) of 36 weeks. Secondary outcome parameters are short term sequelae of cardiovascular failure, comorbidity and adverse events assessed during hospitalization and long-term neurodevelopmental outcome assessed at a corrected age of 2 years. Consequences regarding health economics are evaluated by cost effectiveness analysis and budget impact analysis.

(Continued on next page)
\end{abstract}

\footnotetext{
*Correspondence: tim.hundscheid@radboudumc.nl

'Department of Paediatrics, Division of Neonatology, Radboud university

medical centre Nijmegen, Radboud Institute for Health Sciences, Amalia

Children's Hospital, Internal postal code 804, Geert Grooteplein Zuid 10,

6525, GA, Nijmegen, The Netherlands

Full list of author information is available at the end of the article
}

(c) The Author(s). 2018 Open Access This article is distributed under the terms of the Creative Commons Attribution 4.0 International License (http://creativecommons.org/licenses/by/4.0/), which permits unrestricted use, distribution, and reproduction in any medium, provided you give appropriate credit to the original author(s) and the source, provide a link to the Creative Commons license, and indicate if changes were made. The Creative Commons Public Domain Dedication waiver (http://creativecommons.org/publicdomain/zero/1.0/) applies to the data made available in this article, unless otherwise stated. 
(Continued from previous page)

Discussion: As a conservative approach is gaining interest, we investigate whether in preterm infants, born at a GA less than 28 weeks, with a PDA an expectative management is non-inferior to early treatment with IBU regarding to the composite outcome of mortality and/or NEC and/or BPD at a PMA of 36 weeks.

Trial registration: This trial is registered with the Dutch Trial Register NTR5479 (registered on 19 October 2015), the registry sponsored by the United States National Library of Medicine Clinicaltrials.gov NCT02884219 (registered May 2016) and the European Clinical Trials Database EudraCT 2017-001376-28.

Keywords: Prematurity, Patent ductus arteriosus, Neonatal intensive care unit, Ibuprofen, Expectative management, Ductal ligation, Mortality, Necrotising enterocolitis, Bronchopulmonary dysplasia, Cost-effectiveness

\section{Background}

Controversy exists about the optimal management of a patent ductus arteriosus (PDA) in preterm infants, especially in those born at a gestational age (GA) less than 28 weeks, due to a lack of evidence for any specific treatment including non-intervention [1-12]. There is also no consensus about the diagnostic criteria of a haemodynamically significant PDA (hsPDA). The reported incidence of a PDA in preterm infants is 30-60\%, depending on the used definition, the timing of the diagnosis and the studied population.

PDA has been associated with mortality and major morbidities, such as bronchopulmonary dysplasia (BPD), pulmonary haemorrhage $(\mathrm{PH})$, intraventricular haemorrhage $(\mathrm{IVH})$, necrotising enterocolitis (NEC) and retinopathy of prematurity (ROP). The underlying pathophysiologic mechanism of this might be that a PDA with significant left-to-right shunting results in pulmonary hyperperfusion and systemic hypoperfusion, although any evidence for a causal relationship is lacking [13-19].

There is a large variation in the management of a PDA between centres [20-22]. Pharmacological closure of the PDA is most often attempted by inhibition of prostaglandin synthesis with non-selective cyclooxygenase inhibitors (COXi), such as indomethacin (INDO) or ibuprofen (IBU). By postponing the start of treatment of a PDA, the risk of redundant adverse effects of COXi is decreasing as the postnatal age (PNA) at which COXi is started increases, while the time of exposure to a hsPDA might be prolonged. Some reports suggest that a high dose of IBU might be more effective in ductal closure in preterm infants, especially in those less than 27 weeks' gestation [23-26]. However, in a recent systematic review Ohlsson et al. refrained from recommendations regarding high dose IBU because of the limited number of patients enrolled in the studies [17]. Use of paracetamol has been associated with closure of a PDA in studies with only a limited number of preterm infants [27-35]. Moreover, the high dose of paracetamol $(60 \mathrm{mg} / \mathrm{kg} /$ day $)$ that is used to close the PDA gives rise to concerns about safety in preterm infants [36-38]. Standard ligation after failure of medical closure resulted in an increased incidence of BPD and neurodevelopmental impairment in comparison with delayed ligation in a selected population $[39,40]$. Of interest, an expectative approach after failure of treatment was followed by 'spontaneous' closure in $67-86 \%$ of the patients [39, 41, 42].

Roughly, there are four different management approaches for preterm infants with a PDA: (1) prophylactic treatment; (2) pre-symptomatic ('early') treatment; (3) symptomatic ('late') treatment and; (4) expectative management $[9,12]$.

1. Prophylactic treatment consists of administration of COXi in all patients within a predefined patient group at a PNA less than $24 \mathrm{~h}$. Prophylactic administration of INDO has been shown to reduce the incidence of symptomatic PDA, need for surgical ligation, and severe cerebral haemorrhage, and it seems to reduce the risk of $\mathrm{PH}[14,43]$. However, no effect was found on mortality or neurodevelopmental outcome at the age of 1836 months [44]. Prophylactic IBU administration reduced the need for additional treatment of the PDA, but no effect has been described on the incidence of severe comorbidity [16].

2. Pre-symptomatic treatment is usually timed within the first 3 to 5 days of life. Significant left-to-right shunting can already occur early after birth, whereas clinical signs generally manifest later, with an average delay of 2 days $[45,46]$. Echocardiography is used to identify patients with a potentially increased risk of PDA-associated morbidity [47]. No beneficial effects on relevant neonatal morbidity were found in a systematic review of the administration of INDO for asymptomatic PDA in preterm infants [13].

3. In symptomatic treatment, physicians wait for a possible spontaneous closure of the ductus arteriosus (DA). Treatment is only started when clinical signs and symptoms presumably related to a PDA develop. As formulated by Evans It is the clinical approach that is most widely used but we do not have any evidence to support it' [9]. 
4. Expectative management is characterized by 'watchful waiting' without the intention to actively close the DA. This approach is based on the fact that in a substantial portion of preterm infants the DA will close spontaneously $[9,41,42,48-50]$ and that there is a lack of proven benefit of medical treatment [1-12]. This expectative approach to a PDA in preterm infants is gaining interest. A recent multicentre retrospective study in 28,025 very low birth weight infants $(<1500 \mathrm{~g})$ showed that the annual rate of patients who were not treated for their PDA $(n=12,002)$ increased from $60.5 \%$ in 2008 to $78.3 \%$ in 2014 [51].

\section{Meta-analysis of randomised controlled trials evaluating PDA treatment}

We searched for all randomised controlled trials (RCTs) evaluating PDA treatment in the US National Library of Medicine (Medline), Cochrane Library, EMBASE and ClinicalTrials.gov database, using the Mesh terms: 'infant, newborn' AND 'ductus arteriosus, patent', combined with 'indomethacin' OR 'ibuprofen' OR 'cyclooxygenase inhibitors' OR 'paracetamol'. This search revealed a total of 787 hits. We excluded non-randomised studies and RCTs that are not placebo-controlled. Some eligible studies had to be excluded due to language (non-English) or unavailable full text. A total of 32 RCTs were included in a systematic review $[15,18,44,52-80]$. Data on the outcome parameters were extracted independently by two reviewers ( $\mathrm{WO}$ and $\mathrm{WdB}$ ) and entered into Review Manager Software for meta-analysis (Revman version 5.3 Copenhagen: The Nordic Cochrane Centre, The Cochrane Collaboration, 2014). Random effects meta-analysis of the 32 included studies showed that, when compared with placebo, COXi are effective in ductal closure on the short term, since the risk ratio for failure of ductal closure is $0.44(0.38-0.50)$. However, this was not associated with a reduction in mortality and morbidity (Table 1).
Based on these data, it has been assumed that PDA treatment, although it does lead to a higher rate of ductal closure, does not lead to a significant better outcome. However, critical analysis of the data shows that a substantial part (up to 85\%) of the control group was actually treated for PDA (Fig. 1). So, instead of concluding that PDA treatment does not lead to a better outcome it can only be concluded that there is no significant difference in early versus later or delayed treatment, due to the high amount of treated infants in the control group.

\section{Randomised controlled trials evaluating expectative management}

Until now, no RCT has been published that compares treatment of a PDA with COXi with an expectative approach, i.e. no treatment intended to actively close the PDA. Table 2 gives an overview of recent observational studies describing the outcome of conservative management, that were compared with the Vermont Oxford Network database from 2009 [81-90]. Several studies were excluded due to a high treatment rate in the control group with both INDO (up to 100\%) and/or ligation (up to $72 \%$ ) [39, 91-94]. In addition, the conservative management was rather heterogeneous, ranging from an expectative management to fluid restriction, diuretics and/or adapted ventilator settings. Therefore, although these studies suggest that an expectative approach does not seem to be associated with an increased incidence of neonatal mortality or morbidity, convincing evidence supporting this wait-and-see policy is still lacking, especially in preterm infants born at less than 28 weeks' gestation.

\section{Research gap}

To date, no RCT has been published that compares early treatment of a PDA with COXi in preterm infants less than 28 weeks' gestation with an expectative approach, that is defined as no intervention in relation to the PDA.

Table 1 Meta-analysis of COXi versus placebo in preterm neonates with PDA

\begin{tabular}{lllll}
\hline Outcome & Studies & Participants & Risk Ratio & 95\%-Cl \\
\hline Mortality & 31 & 3534 & 0.98 & $0.84-1.13$ \\
BPD (total) & 23 & 3531 & 1.07 & $0.98-1.16$ \\
$\quad$ BPD (oxygen need at PNA 28 days) & 16 & 1395 & 1.07 & $0.94-1.22$ \\
$\quad$ BPD (oxygen need at PMA 36 weeks) & 8 & 2136 & 1.06 & $0.95-1.20$ \\
NEC & 23 & 3285 & 1.05 & $0.83-1.32$ \\
Death or BPD at PMA 36 weeks & 7 & 2096 & 1.05 & $0.97-1.14$ \\
IVH & 20 & 3150 & 0.98 & $0.88-1.10$ \\
Failure of ductal closure & 23 & 1619 & 0.44 & $0.38-0.50$ \\
\hline
\end{tabular}

Cl, Confidence interval; BPD, Bronchopulmonary dysplasia; PNA, Postnatal age; PMA, Postmenstrual age; NEC, Necrotising enterocolitis (any grade); IVH, Intraventricular haemorrhage (any grade) 


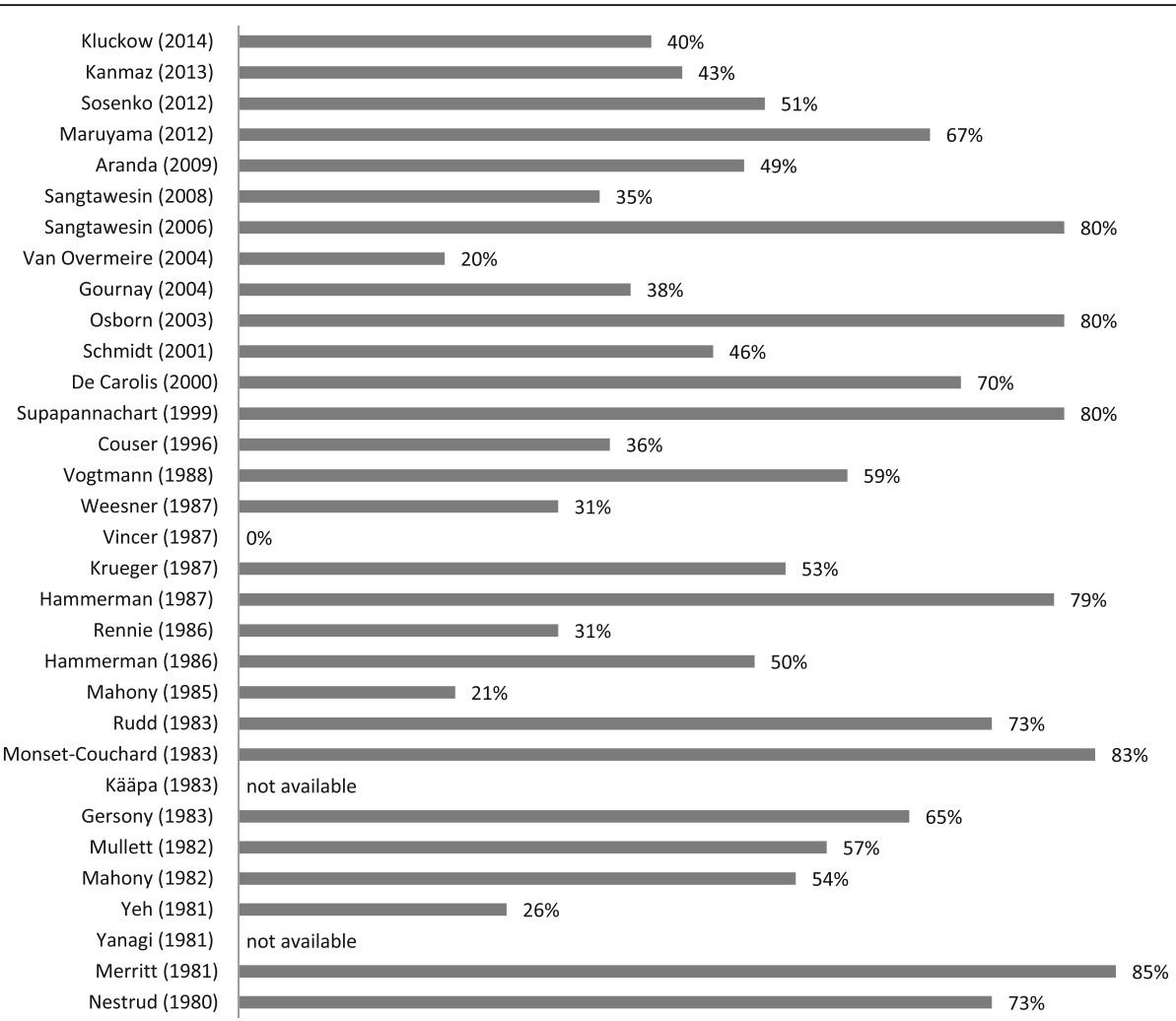

Fig. 1 Percentage of patients in the control group eventually treated for their PDA

\section{Methods/design \\ Study aims}

Our aim is to investigate whether in preterm infants, born at a GA less than 28 weeks, with a PDA (diameter $>1.5 \mathrm{~mm}$ ) at a PNA $<72 \mathrm{~h}$, an expectative management is non-inferior to early treatment with regard to the composite of mortality and/or NEC (Bell stage $\geq$ IIa) and/or BPD at a postmenstrual age (PMA) of 36 weeks.

\section{Study design and settings}

Multicentre, randomised, non-inferiority trial conducted in level III neonatal intensive care units (NICUs) in Europe (BeNeDuctus trial). A flow chart of the study design is shown in Fig. 2.

\section{Ethical consideration}

After analysis of the results from many RCTs it has been concluded that treatment of a PDA does not result in a decreased rate of mortality and morbidity. A conservative approach towards a PDA is increasingly used in many centres worldwide without a concomitant increase in mortality or morbidity [51, 81-89, 95]. The administration of IBU in the treatment arm of this trial does not pose an extra burden on the patient as it is considered routine treatment in preterm infants with a PDA in many NICUs. Patients who are not treated with IBU are refrained from potential adverse effects of this drug. All patients in this study are treated in accordance with current (inter)national guidelines and local protocols regarding neonatal intensive care management. All primary and secondary outcome parameters are evaluated as part of routine care in Belgium and the Netherlands. No extra investigations, apart from the blinded echocardiogram in the expectative treatment arm, or interventions are needed in this study. Gentle handling of the preterm during echocardiography has been shown not to disturb cardiorespiratory stability $[96,97]$.

\section{Definitions}

Transductal diameter of a PDA is measured as described by Kluckow and Evans [98]. Of note, the inclusion criterion of a transductal diameter $>1.5 \mathrm{~mm}$ is not meant to define hemodynamic significance. It is only used to exclude randomisation of preterm infants with a nearly closed DA. A DA is considered to be closed when the transductal diameter measures less than $0.5 \mathrm{~mm}$ or it cannot be visualized using colour Doppler imaging. NEC is classified according to the modified Bell staging criteria [99]. BPD is defined as the need for supplemental oxygen at a PMA of 36 weeks and diagnosed following international standard criteria by Bancalari, including an oxygen reduction test according to Walsh [100, 101]. 


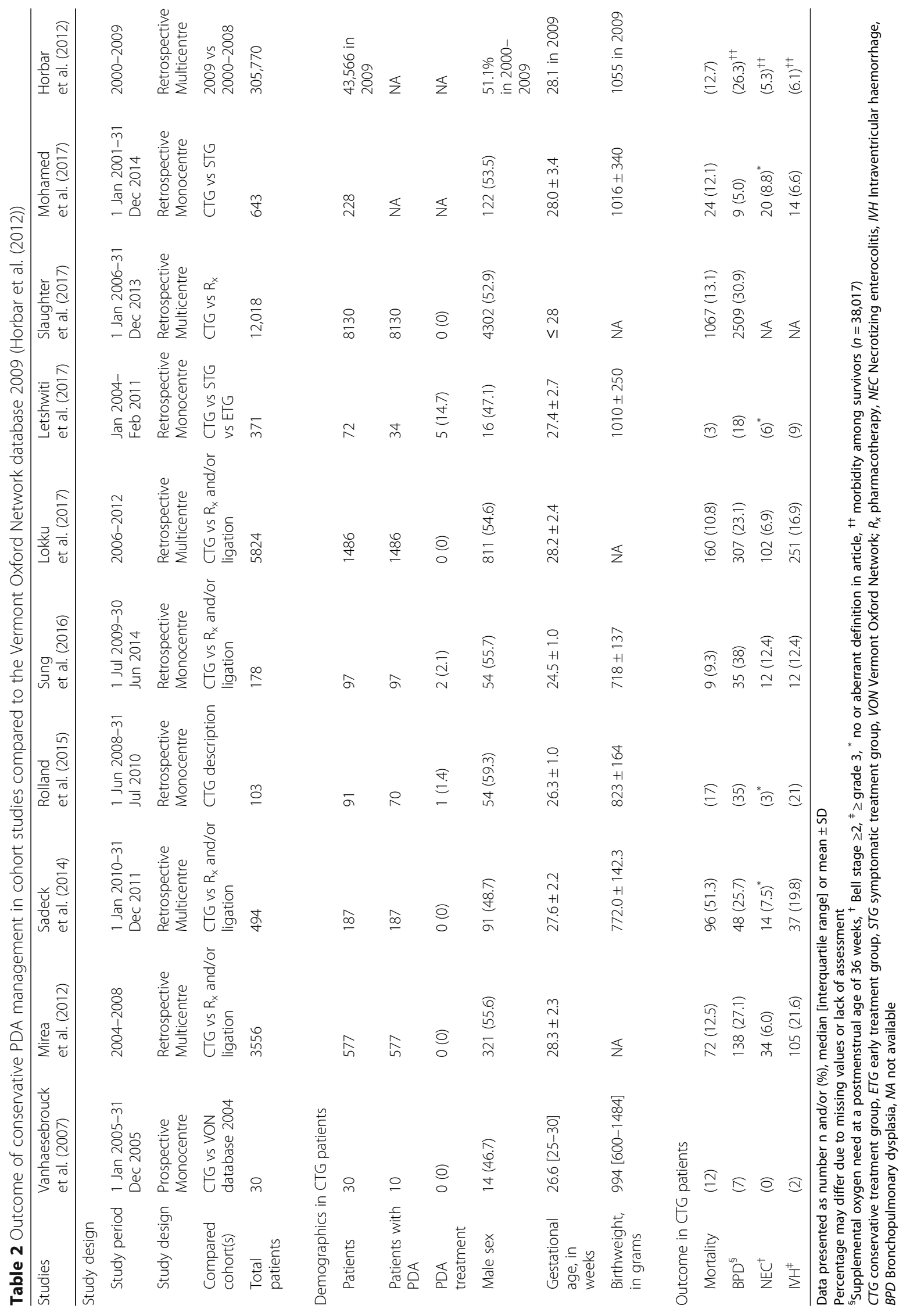




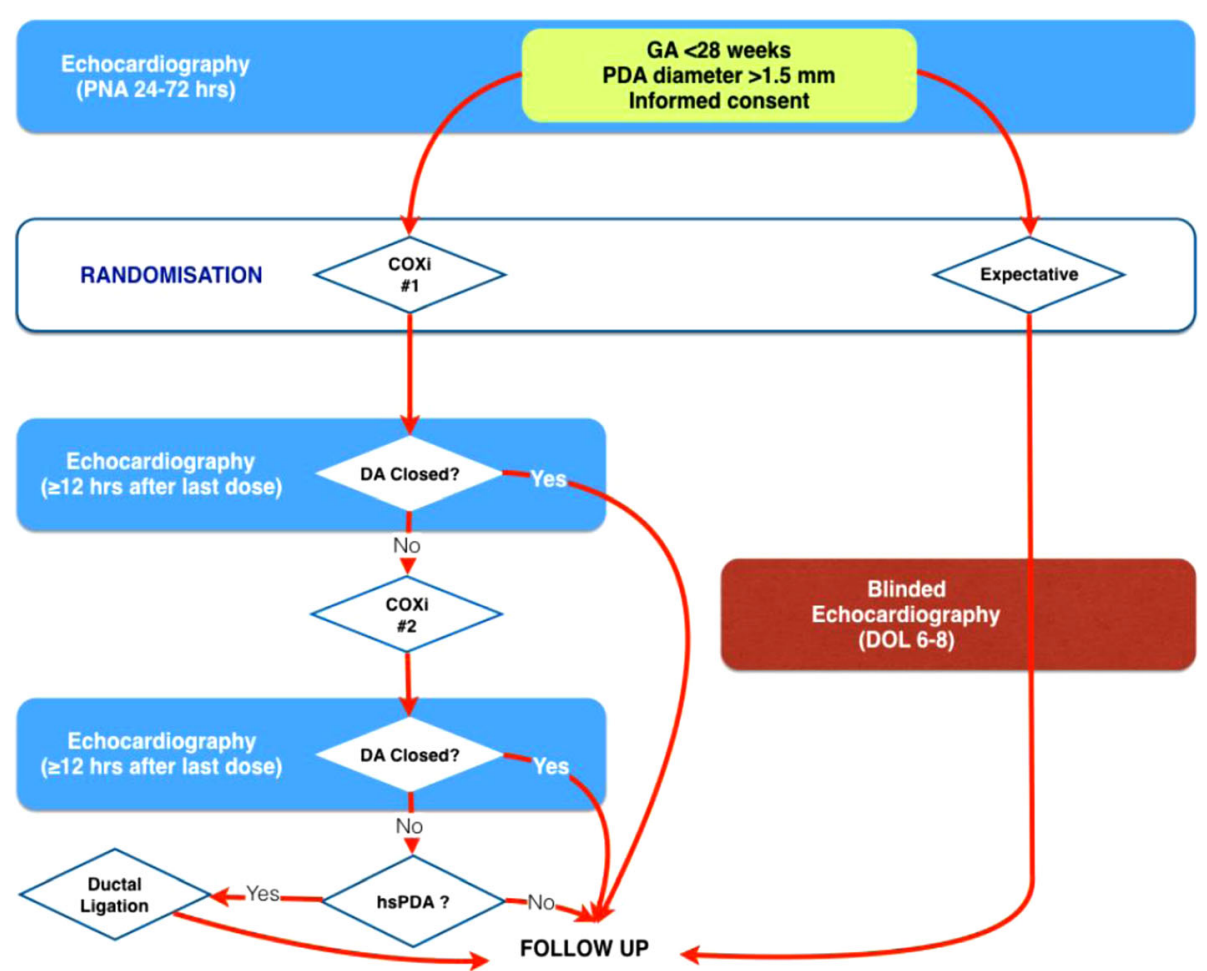

Fig. 2 Flow chart of the study design. COXi, cyclo-oxygenase inhibitor; DA, Ductus arteriosus; DOL, day of life; GA, gestational age; (hs)PDA, (Haemocyamic significant) patent ductus arteriosus; PNA, postnatal age

Hypotension is defined as a mean arterial blood pressure less than the gestational age in weeks. IVH is classified according to the classification by Volpe [102]. Periventricular echogenicity is classified according to the classification by Hashimoto et al. [103]. Sepsis is defined as a positive blood culture for which the patient has been treated with antibiotics. ROP is classified according to the international classification [104].

Preterm infants born at a GA of less than 28 weeks, admitted to a level III NICU, both inborn and outborn, are eligible.

Inclusion criteria are (1) preterm infants born at a GA $<28$ weeks; (2) PNA between 24 and $72 \mathrm{~h}$; (3) PDA diameter $>1.5 \mathrm{~mm}$ and predominantly left-to-right transductal shunt ( $\geq 66 \%$ of the cardiac cycle); and (4) signed informed consent obtained from parent(s) or representative(s). Exclusion criteria are (1) contraindication(s) for the administration of IBU (e.g. active bleeding, especially intracranial or gastrointestinal haemorrhage; thrombocytopenia $(<50 \times 10 \mathrm{E} 9 / \mathrm{L})$; renal failure (raised creatinine $(>120 \mu \mathrm{mol} / \mathrm{L})$ or oliguria $(<0.5 \mathrm{~mL} /$ $\mathrm{kg} / \mathrm{h})$ ); known or suspected NEC); (2) use of COXi prior to randomisation; (3) persistent pulmonary hypertension (ductal right-to-left shunt $\geq 33 \%$ of the cardiac cycle); (4) congenital heart defect, other than PDA and/or patent foramen ovale; (5) life-threatening congenital defects or; (6) chromosomal abnormalities and/or congenital anomalies associated with abnormal neurodevelopmental outcome.

\section{Primary outcome definition}

The primary endpoint is the composite of mortality, and/or NEC (Bell stage $\geq$ IIa), and/or BPD at a PMA of 36 weeks.

\section{Secondary outcome definition}

During the first eleven postnatal days there will be a daily recording in the electronic Case Report Form (eCRF) of the following, first available parameters in the morning: (a) blood pressure (systolic, diastolic and mean pressure) in $\mathrm{mmHg}$; (b) heart rate in beats per minute; (c) urine output in $\mathrm{mL} / \mathrm{kg} / \mathrm{h}$ in the last 8-12 h; (d) actual weight in grams; (e) total daily fluid intake in $\mathrm{mL} / \mathrm{kg} /$ $24 \mathrm{~h}$ and; (f) total enteral intake in $\mathrm{mL} / \mathrm{kg} / 24 \mathrm{~h}$.

Secondary endpoints are divided in three categories:

1. Short term sequelae of cardiovascular failure, such as (a) hypotension and; (b) need for cardiovascular support.

2. Adverse events during hospitalization, such as (a) BPD at a PNA of 28 days; (b) mortality at a PNA of 28 days and at hospital discharge; (c) modes and duration of respiratory support; (d) total days of oxygen supplementation; (e) incidence of 
pulmonary air leakage (e.g. pneumothorax); (f) $\mathrm{PH}$; (g) IVH; (h) periventricular echogenicity; (i) NEC; (j) gastrointestinal bleeding; (k) spontaneous intestinal perforation; (l) time to full enteral feeding; (m) sepsis; (n) ROP; (o) adverse effects of IBU; (p) need for surgical ligation of PDA and; (q) length of hospitalization.

3. Neurodevelopmental outcome is assessed in all Dutch and Belgian children in the National Neonatal Follow Up Program at a corrected age of 24 months by (a) paediatric and neurologic examination; (b) cognitive assessment with Bayley Scales of Infant and Toddler Development, Third Dutch Edition (BSID-III-NL); (c) behavioural assessment with Child Behavior Check List (CBCL), Teacher Report Form (TRF) questionnaire and; (d) motor function with Movement Assessment Battery for Children, Second Dutch Edition (Movement ABC 2-NL). For non-Dutch or Belgian children equivalent assessments may be used.

\section{Economic evaluation}

The economic evaluation is performed along-side the randomised clinical study. We will conduct both a cost-effectiveness analysis (CEA) and a budget impact analysis (BIA).

\section{Cost-effectiveness analysis}

The potential efficiency of expectative management of PDA in preterm infants with a PDA is compared to the heterogeneous usual care for preterm infants with a PDA. The CEA is performed from a societal perspective. We hypothesize that expectative management is the cost-effective alternative, because it saves on medical treatments and diagnostics at non-inferior effectiveness. The economic evaluation is based on the general principles of a CEA. Primary outcome measures for the economic evaluation, considering the 24 months follow-up period, are (in)direct costs and composite of survival and/or NEC and/or BPD. When this composite does not differ between an expectative management and usual care the cost-effectiveness decision rule will be cost minimization, else it will be cost associated with a gain or loss in survival and/or NEC and/or BPD. This efficiency outcome will be computed and uncertainty will be determined using the bootstrap method. If a difference between the two alternative treatments occurs, a cost-effectiveness acceptability curve will be derived that is able to evaluate efficiency by using different thresholds (Willingness To Pay) for a combined survival effect. The impact of uncertainty surrounding deterministic parameters on the efficiency outcome will be explored using one-way sensitivity analyses on the range of extremes.
The cost analysis exists of two main parts. First, on patient level, volumes of care will be measured prospectively over the time path of the clinical study using the eCRF and/or medical records and the inpatient treatment facilities administration system to collect information on for example: consultation paediatric cardiologist, echocardiography, chest X-ray, medication, intensive care transport and ductal ligation. Second per arm full cost-prices will be determined using the Dutch guideline [105], or else real cost prices via activity based costing or centre-specific cost information. Productivity losses for parents will be estimated using a patient-based iMTA Productivity Cost Questionnaire adapted to parents at a postnatal age of 4 weeks and a corrected age of 6,12 and 24 months [106]. The questionnaire is given to the parents by mail together with a post-paid envelope or sent via electronic mail. The friction cost-method will be applied following the Dutch guidelines [105]. The cost analysis will be performed using a mixed model approach with centre as random coefficient and potential confounders as fixed.

\section{Budget impact analysis}

The aim of this BIA is to assess the financial consequences of implementing an expectative management in the Dutch health care system in the short-to-medium term from the budget holder's perspective [107]. The BIA base-case perspectives are respectively societal, health insurance/third party payer and health care. A global average cost per patient for expectative management is $€ 89,000$ and for the usual care $€ 92,000$. Multiplied by the yearly number of preterm neonates with a PDA in the Netherlands $(n=$ 270) gives a global impression of the magnitude of the budget impact, namely $€ 24,000,000$ compared to $€ 24,800,000$. This provides a yearly budgetary saving of about $€ 800,000$. At least four scenarios will be considered, namely (1) current care; (2) immediate $100 \%$ expectative management; (3) gradual implementation of expectative management and; (4) partial implementation of expectative management. The BIA will be assessed through (decision analytical) modelling and analysed, if possible, in a probabilistic way [108].

\section{Randomisation process}

In the absence of exclusion criteria, eligible patients will be randomised to either the expectative management arm or the medical treatment arm. The randomisation is coordinated centrally and web-based. Randomisation will be per centre and stratified according to GA stratum (Stratum A: GA $<26^{0 / 7}$ weeks; Stratum B: GA $26^{0 / 7}-27^{6 / 7}$ weeks). The block size will vary in a range from four to eight. The intention is to randomise multiple birth infants independently, unless there is an explicit request from the 
parents/caretakers to expose the siblings to the same treatment.

\section{Withdrawal and replacement of individual subjects}

The investigator or attending physician can decide to withdraw a subject from the study for urgent medical reasons. If they wish, parents or caregivers can leave the study at any time for any reason. Only patients that are withdrawn from the study at the request of parents or caregivers will be replaced. The total number of patients that can be replaced is limited to twenty-five. Infants who are withdrawn from the study, will receive standard of care, including regular follow up after discharge, with assessment of neurodevelopmental outcome. Patients in the expectative management arm that meet the criteria for open label treatment with IBU (Table 3) and/or surgical ligation (Table 4) will remain in follow up and are therefore not withdrawn from the study.

\section{Treatment arms}

\section{Expectative management arm (intervention)}

Patients randomised to the expectative management arm will not receive $\mathrm{COXi}$, including for indications other than closure of the DA. No (additional) putative interventions to prevent or treat a PDA, for example fluid restriction or diuretics for that purpose only, are allowed. When the attending physician thinks that the patient is in danger when being deprived from treatment with COXi, open label treatment can only be considered when pre-specified criteria are met (Table 3). To be informed about the natural course of ductal closure echocardiography is performed at the end of the first week of

Table 3 Open label criteria

I. Exclusion of other causes of cardiovascular failure (e.g. sepsis or congenital heart defect)

AND

II. Clinical findings of cardiovascular failure secondary to significant ductal left-to-right shunting:

a. Signs of systemic hypoperfusion (refractory systemic hypotension and/or elevated serum lactate concentration (> $2.5 \mathrm{mmol} / \mathrm{L})$ ) and;

b. Signs of pulmonary hyperperfusion (prolonged ventilator dependency).

AND

III. Echocardiographic findings of significant ductal left-to-right shunting

a. Diameter of PDA > $1.5 \mathrm{~mm}$, and;

b. Unrestricted ductal left-to-right shunting ('pulsatile pattern'): end-diastolic flow velocity $<50 \%$ of peak flow velocity, and;

c. End-diastolic flow velocity left pulmonary artery $>0.3 \mathrm{~m} / \mathrm{s}$, and; d. Left atrial to aortic ratio $>1.5$.

AND

a. Severe left ventricular failure (mitral regurgitation), and;

b. Disturbed end-organ perfusion (retrograde diastolic blood flow in descending aorta).
Table 4 Ligation criteria

I. Exclusion of other causes of cardiovascular failure (e.g. sepsis or congenital heart defect)

AND

II. Clinical findings of cardiovascular failure secondary to significant ductal left-to-right shunting:

a. Signs of systemic hypoperfusion (refractory systemic hypotension and/or elevated serum lactate concentration (> $2.5 \mathrm{mmol} / \mathrm{L})$ ) and/or;

b. Signs of pulmonary hyperperfusion (prolonged ventilator dependency).

AND

III. Echocardiographic findings of significant ductal left-to-right shunting

a. Diameter of PDA > $1.5 \mathrm{~mm}$, and

b. Unrestricted ductal left-to-right shunting ('pulsatile pattern'): end-diastolic flow velocity $<50 \%$ of peak flow velocity, and/or;

c. End-diastolic flow velocity left pulmonary artery $>0.3 \mathrm{~m} / \mathrm{s}$, and/or;

d. Left atrial to aortic ratio $>1.5$. AND/OR

a. Severe left ventricular failure (mitral regurgitation), and/or:

b. Disturbed end-organ perfusion (retrograde diastolic blood flow in descending aorta).

life, but only when it is feasible for the clinical team to remain blinded for the results.

\section{Medical treatment arm (control)}

Patients in the medical treatment arm receive $\mathrm{COXi}$ as soon as possible after randomisation, preferably within 3h. In this study IBU is used, because it seems to be as effective in ductal closure in preterm infants as INDO. Besides, IBU might have less side-effects than INDO, since IBU reduces the risk of NEC and transient renal insufficiency [17], does not affect mesenteric blood flow, has less effect on renal perfusion [109-111], and influences cerebral blood flow in a lesser extent [111-114]. The dosing scheme for IBU is according to local guidelines. The preferred route of administration of IBU is intravenously. However, this is at the discretion of the attending physician, since enteral administration appears at least as effective [17, 115-118].

Echocardiographic re-evaluation is performed at least $12 \mathrm{~h}$ after the last (third) dose of the first IBU course. If the DA is found to be closed, no further analysis or treatment is needed regarding the DA. When the DA has not closed, a second course of IBU is started at least $24 \mathrm{~h}$ after the third dose of the first course, in a similar dosage. 12 to $24 \mathrm{~h}$ after the last (sixth) dose of the second course echocardiography is performed again. If the DA is found to be closed, no further analysis or treatment is needed regarding the DA. When the DA failed to close after two courses of IBU and is still classified as a hsPDA, ductal ligation can be considered, when the ligation criteria are met (Table 4). 


\section{Co-interventions}

It is essential that neonatal management is similar in both study arms except for the prescription of IBU and routine echocardiography at the end of the drug course(s) in the medical treatment arm. All patients in this study will be treated according to current (inter)national guidelines and local protocols regarding neonatal intensive care management. When ductal closure has not been documented before discharge, ductal patency is echocardiographically examined in both arms of the study, when this is indicated by the local paediatric cardiologist and only at a date after the primary outcomes have been established, after a postmenstrual age of 36 weeks. Echocardiographic pictures and movies are stored and collected for blinded re-analysis at the end of the study.

All prognostic relevant co-interventions and conditions will be documented, using the standard medical records, such as (a) administration of antenatal steroids; (b) maternal disease (e.g. pre-eclampsia); (c) maternal medication, especially COXi; (d) mode of delivery; (e) multiple birth; (f) duration of rupture of membranes; (g) GA at birth; (h) birth weight; (i) Apgar scores at 5min; (j) umbilical blood gas analysis; (k) resuscitation after birth; (l) surfactant administration, and; (m) postnatal steroids.

\section{Sample size, power and statistical methods Sample size}

Based on data from the Dutch Perinatal Registry the incidence of our primary outcome measures mortality, NEC and BPD is 20, 10 and $15 \%$ respectively in preterm infants less than 28 weeks' gestation [119]. Non-inferiority is defined as a significant difference in the primary outcome parameter between the two arms of less than $10 \%$. In other words, the $95 \%$ confidence interval of the observed difference between an expectative approach and COXi treatment should not exceed the non-inferiority margin of $10 \%$. With an estimated a priori risk for the composite of mortality and/or NEC and/or BPD at 36 weeks PMA of $35 \%$, a one sided type I error of $5 \%$ and a power of $80 \%$, the sample size to exclude a non-inferiority margin of $10 \%$ for the difference of proportion of participants reaching the primary outcome parameter is 564 patients, being 282 patients in each arm. This sample size was calculated using PASS 2008, version 08.0.8 NCSS.

\section{Time frame}

Based on retrospective data a total of 540 preterm neonates with a GA less than 28 weeks will be born yearly in The Netherlands, of whom approximately 270 (50\%) will have a PDA at a PNA of 24-72 h. With an estimated inclusion rate of $66 \%(n=178)$, patient recruitment will take approximately 3 years.

\section{Data analysis}

Treatment effects for the dichotomous clinical outcomes will be reported using risk differences with 95\% confidence interval. Normally distributed data will be presented as mean \pm standard deviations, uneven distributed data as medians with interquartile ranges. Categorical data will be analysed using the Chi-square for twoand multiway tables. Continuous data will be analysed using the Student's $\mathrm{t}$ test. Both intention-to-treat and per-protocol analyses will be employed. Statistical significance is defined as a $p$-value $<0.05$. For the primary outcome a $95 \%$ one sided confidence interval for the risk difference will be calculated and when based on this interval a difference of $10 \%$ or more can be excluded, non-inferiority will be concluded.

\section{Adverse events and monitoring Data safety monitoring board}

An external Data Safety Monitoring Board (DSMB) will monitor the safety, validity, and credibility of the trial in order to protect the patients and will provide the trial's Steering Committee with recommendations regarding continuation or cessation of the trial. The normal distribution between the components of the primary outcome parameter will be closely monitored by the DSMB. The DSMB is composed of three individuals: a neonatologist with extensive knowledge about PDA, a statistician who has experience with clinical trials and a paediatric cardiologist with extensive knowledge about neonatal haemodynamics. The composition, tasks, responsibilities and working procedures of the DSMB are described in a charter. The DSMB will meet to discuss the findings of the safety interim analyses. These will be conducted when 15, 30, 50 and $75 \%$ of the data have been gathered.

The DSMB charter states that there are two possible reasons for stopping the study early, namely concerns for safety and futility. In principle, the trial will not be stopped early before the minimum number of evaluable patients required $(n=564)$ are included for beneficial effect of IBU treatment on the primary outcome. Unless there is an unacceptably high rate of mortality in either the IBU or expectative group, this is to preserve the power for evaluation of neurodevelopmental outcome at 2 years corrected age. Hence, the interim analyses will not be associated with alpha spending.

\section{Reporting adverse events}

Adverse events are defined as any undesirable experience occurring to a subject during the study, whether or not considered related to the interventions in this study. All adverse events observed by the parents, caretakers or 
the investigator and staff will be recorded in the eCRF until discharge home.

A serious adverse event (SAE) is any untoward medical occurrence or effect that at any dose (a) results in death; (b) is life threatening (at the time of the event); (c) requires hospitalization or prolongation of existing inpatients' hospitalization; (d) results in persistent or significant disability or incapacity, and; (e) is a congenital anomaly or birth defect (not applicable in this study). Any other important medical event that may not result in death, be life threatening, or require hospitalization, may be considered a SAE when, based upon appropriate medical judgement, the event may jeopardize the subject or may require an intervention to prevent one of the outcomes listed above. An elective hospital admission will not be considered a SAE.

All SAEs will be reported, by the coordinating principle investigator (PI) to the DSMB and through the web portal ToetsingOnline to the accredited medical ethics committee (MEC) that approved the protocol. In non-Dutch centres the PI will report to the coordinating PI in The Netherlands and to the relevant national authorities. All adverse events will be followed until they have abated, or until a stable situation has been reached. SAEs need to be reported till end of study.

This study population has a high risk of serious complications, which are inherent to their vulnerable condition and unrelated to the intervention which is under evaluation in this trial, the so-called 'context-specific SAEs'. These are included in the primary and secondary outcomes of this study and are recorded in the eCRF by the PI. Immediate and individual reporting of all these condition related complications will not enhance the safety of the study, so they will be presented to the DSMB and MEC once a year [120-122].

\section{Current status of trial}

The first patient has been included in the study in December 2016.

\section{Discussion}

A growing number of clinicians believe the PDA is an innocent bystander, since no causal relationship has been proven between a hsPDA and the risk of conditions related to pulmonary hyperperfusion (e.g. PH and BPD) and/or systemic hypoperfusion (e.g. NEC). An expectative management is gaining interest, although convincing evidence to support this management is lacking, since there is no RCT available comparing treatment with an expectative approach. We found only one small study describing a prospective cohort and several retrospective studies comparing two or three time eras with comparison of different management approaches in preterm infants with a persistent PDA [81-89]. These observational studies have not shown a concomitant increase in mortality and morbidity related to a decrease in active ductal closure.

In this study we randomise preterm infants born at less than 28 weeks' gestation to two different intentions regarding the management of a PDA. Our primary hypothesis is that an expectative treatment is non-inferior to early treatment of a PDA in premature infants born at a GA less than 28 weeks. In the treatment arm the PDA is regarded a plausible cause of neonatal mortality and morbidity secondary to an increased pulmonary perfusion at the expense of systemic hypoperfusion, while in the expectative management arm the PDA is accepted as a non-pathological phenomenon and PDA is merely regarded as a marker of immaturity. It was deliberately chosen not to perform a placebo-controlled trial, because it is our conviction that then the focus would be on treatment of a PDA in the study population with an associated increased risk of open label treatment, as has occurred in former RCTs. To further minimize the risk of contamination of the expectative management group we defined strict open label criteria.

We aim to gain more insight in the natural course of the PDA in the expectative management arm. Therefore, an echocardiogram, that is blinded for the attending clinical team, is performed at the end of the first week. This trial will be protected from selection bias by using concealed, stratified and blocked randomisation. Patient characteristics will be collected from all eligible infants that are not included in this study in order to assess any potential recruitment bias.

If this trial supports our hypothesis that an expectative management is non-inferior to early closure, there will be a reduction in costs, which will be calculated with the CEA en BIA. Not only in this economic perspective an expectative treatment would be more interesting, also vulnerable premature infants will be prevented from potential adverse effects from medical or surgical treatment.

\footnotetext{
Abbreviations

BIA: Budget impact analysis; BPD: Bronchopulmonary dysplasia; CEA: Cost effectiveness analysis; COXi: Cyclooxygenase inhibitors; DA: Ductus arteriosus; DSMB: Data safety monitoring board; eCRF: Electronic case report form; GA: Gestational age; hsPDA: Haemodynamically significant patent ductus arteriosus; IBU: Ibuprofen; INDO: Indomethacin; IVH: Intraventricular haemorrhage; MEC: Medical ethics committee; NEC: Necrotising enterocolitis; NICU(s): Neonatal intensive care unit(s); PDA: Patent ductus arteriosus; PH: Pulmonary haemorrhage; PI(s): Principle investigator(s); PMA: Postmenstrual age; PNA: Postnatal age; RCT(s): Randomised controlled trial(s); ROP: Retinopathy of prematurity; SAE(s): Serious adverse event(s)
}

\section{Acknowledgements}

We would like to thank K. Deckers and D. Nuytemans, research nurses, and J.H. Gillissen, head of the paediatric drug research centre of the Department of Paediatrics of the Radboudumc Amalia Children's Hospital for their invaluable support. 


\section{Funding}

This trial is funded by ZonMw - The Netherlands Organization for Health Research \& Development (project number 843002622).

\section{Availability of data and materials}

The results will be presented at scientific meetings and published in peer reviewed medical journals. The data that support the findings of this study are available from the corresponding author upon reasonable request. There will be an embargo on the data for 2 to 5 years.

\section{Authors' contributions}

WPB, WO, PD, AHLCK and W were involved in drafting the conception and design of the study. All other authors were involved in the final consensus process of the protocol and contributed significantly to the final version. $\mathrm{TH}$ and WPB drafted the manuscript and all other authors read, edited and approved the final manuscript.

\section{Ethics approval and consent to participate}

This study has been approved by the MEC of the Radboud University (CMO Arnhem-Nijmegen; Number 2016-2552/NL57885.091.16). Neonates are only included after written informed consent is obtained from their parents or caregivers.

\section{Consent for publication}

Not applicable.

\section{Competing interests}

The authors declare that they have no competing interests.

\section{Publisher's Note}

Springer Nature remains neutral with regard to jurisdictional claims in published maps and institutional affiliations.

\section{Author details}

${ }^{1}$ Department of Paediatrics, Division of Neonatology, Radboud university medical centre Nijmegen, Radboud Institute for Health Sciences, Amalia Children's Hospital, Internal postal code 804, Geert Grooteplein Zuid 10, 6525, GA, Nijmegen, The Netherlands. ²Department of Neonatology, Academic Medical Centre Amsterdam, Emma Children's hospital, Meibergdreef 9, 1105, AZ, Amsterdam-Zuidoost, The Netherlands. ${ }^{3}$ Department of Paediatrics, Division of Neonatology, Cliniques Universitaires de Bruxelles, Erasme Hospital, Route de Lennik 808, 1070 Brussels, Belgium. ${ }^{4}$ Department of Paediatrics, Division of Neonatology, University Medical Centre Groningen, Beatrix Children's Hospital, Hanzeplein 1, 9713, GZ, Groningen, The Netherlands. ${ }^{5}$ Department of Paediatrics, Division of Neonatology, VU University Medical Centre Amsterdam, De Boelelaan 1117, 1081, HV, Amsterdam, The Netherlands. ${ }^{6}$ Department of Neonatology, Maxima Medical Centre Veldhoven, de Run 4600, Postbus 7777, 5500, MB, Veldhoven, The Netherlands. ${ }^{7}$ Department of Paediatrics, Division of Neonatology, Maastricht University Medical Centre, P. Debyelaan 25, 6229, HX, Maastricht, The Netherlands. ${ }^{8}$ Department of Paediatrics, Division of Neonatology, Erasmus Medical Centre Rotterdam, Sophia Children's Hospital, 's Gravendijkwal 230, 3015, CE, Rotterdam, The Netherlands. 'Department of Paediatrics, Division of Neonatology, Leiden University Medical Centre, Willem Alexander Children's Hospital, Albinusdreef 2, 2333, ZA, Leiden, The Netherlands. ${ }^{10}$ Department of Paediatrics, Division of Neonatology, University Medical Centre Utrecht, Utrecht University, Wilhelmina Children's Hospital, Lundlaan 6, 3584, EA, Utrecht, The Netherlands. ${ }^{11}$ Department of Paediatrics, Division of Neonatology, Isala Women's and Children's Hospital Zwolle, Dokter van Heesweg 2, 8025, AB, Zwolle, The Netherlands. ${ }^{12}$ Department of Neonatology, UZ Brussel - Vrije Universiteit Brussel, Laarbeeklaan 101, 1090 Brussels, Belgium. ${ }^{13}$ Department of Paediatrics, Division of Neonatology, Antwerp University Hospital, Wilrijkstraat 10, 2650 Edegem, Belgium. ${ }^{14}$ Department of Paediatrics, Division of Neonatology, Hôpital Universitaire des Enfants Reine Fabiola, Bruxelles, Jean Joseph Crocqlaan 15, 1020 Brussels, Belgium. ${ }^{15}$ Department of Paediatrics, Division of Neonatology, Cliniques Universitaires St Luc, Avenue Hippocrate 10, 1200 Brussels, Belgium. ${ }^{16}$ Department of Paediatrics, Division of Neonatology, Ghent University Hospital, De Pintelaan 185, 9000 Ghent, Belgium. ${ }^{17}$ Department of Health Evidence, Radboud university medical centre, Geert Grooteplein Zuid 10, 6525, GA, Nijmegen, The Netherlands.
Received: 27 February 2018 Accepted: 9 July 2018

Published online: 04 August 2018

\section{References}

1. Bose $\mathrm{CL}$, Laughon M. Treatment to prevent patency of the ductus arteriosus: beneficial or harmful? J Pediatr. 2006;148(6):713-4.

2. Bose $\mathrm{CL}$, Laughon MM. Patent ductus arteriosus: lack of evidence for common treatments. Arch Dis Child Fetal Neonatal Ed. 2007;92(6):F498-502.

3. Laughon MM, Simmons MA, Bose CL. Patency of the ductus arteriosus in the premature infant: is it pathologic? Should it be treated? Curr Opin Pediatr. 2004;16(2):146-51.

4. Benitz WE. Treatment of persistent patent ductus arteriosus in preterm infants: time to accept the null hypothesis? J Perinatol: official journal of the California Perinatal Association. 2010;30(4):241-52.

5. Benitz WE. Learning to live with patency of the ductus arteriosus in preterm infants. J Perinatol: official journal of the California Perinatal Association. 2011;31(Suppl 1):S42-8.

6. Benitz WE. Patent ductus arteriosus: to treat or not to treat? Arch Dis Child Fetal Neonatal Ed. 2012;97(2):F80-2.

7. Benitz WE, Committee on F, Newborn AAoP. Patent Ductus Arteriosus in Preterm Infants. Pediatrics. 2016;137(1):e20153730.

8. Clyman RI, Couto J, Murphy GM. Patent ductus arteriosus: are current neonatal treatment options better or worse than no treatment at all? Semin Perinatol. 2012;36(2):123-9.

9. Evans N. Preterm patent ductus arteriosus: a continuing conundrum for the neonatologist? Seminars in fetal \& neonatal medicine. 2015;20(4):272-7.

10. Jain A, Shah PS. Diagnosis, evaluation, and Management of Patent Ductus Arteriosus in preterm neonates. JAMA Pediatr. 2015:169(9):863-72.

11. Perez KM, Laughon MM. What is new for patent ductus arteriosus management in premature infants in 2015? Curr Opin Pediatr. 2015;27(2): 158-64.

12. Sallmon $H$, Koehne $P$, Hansmann $G$. Recent advances in the treatment of preterm newborn infants with patent ductus arteriosus. Clin Perinatol. 2016; 43(1):113-29.

13. Cooke L, Steer P, Woodgate P. Indomethacin for asymptomatic patent ductus arteriosus in preterm infants. The Cochrane database of systematic reviews. 2003:2:CD003745.

14. Fowlie PW, Davis PG, McGuire W. Prophylactic intravenous indomethacin for preventing mortality and morbidity in preterm infants. The Cochrane database of systematic reviews. 2010;7:CD000174.

15. Kluckow M, Jeffery M, Gill A, Evans N. A randomised placebo-controlled trial of early treatment of the patent ductus arteriosus. Arch Dis Child Fetal Neonatal Ed. 2014:99(2):F99-F104.

16. Ohlsson A, Shah SS. Ibuprofen for the prevention of patent ductus arteriosus in preterm and/or low birth weight infants. The Cochrane database of systematic reviews. 2011;7:CD004213.

17. Ohlsson A, Walia R, Shah SS. Ibuprofen for the treatment of patent ductus arteriosus in preterm or low birth weight (or both) infants. The Cochrane database of systematic reviews. 2015;2:CD003481.

18. Sosenko IR, Fajardo MF, Claure N, Bancalari E. Timing of patent ductus arteriosus treatment and respiratory outcome in premature infants: a double-blind randomized controlled trial. J Pediatr. 2012;160(6):929-35. e921

19. Brooks JM, Travadi JN, Patole SK, Doherty DA, Simmer K. Is surgical ligation of patent ductus arteriosus necessary? The western Australian experience of conservative management. Arch Dis Child Fetal Neonatal Ed. 2005;90(3): F235-9.

20. Lee HC, Durand DJ, Danielsen B, Duenas GV, Powers RJ. Hospital variation in medical and surgical treatment of patent ductus arteriosus. Am J Perinatol. 2015;32(4):379-86.

21. Laughon M, Bose C, Clark R. Treatment strategies to prevent or close a patent ductus arteriosus in preterm infants and outcomes. J Perinatol: official journal of the California Perinatal Association. 2007;27(3):164-70.

22. Jansen EJ, Dijkman KP, van Lingen RA, de Vries WB, Vijlbrief DC, de Boode WP, Andriessen P. Using benchmarking to identify inter-Centre differences in persistent ductus arteriosus treatment: can we improve outcome? Cardiol Young. 2017:1-9.

23. Desfrere L, Zohar S, Morville P, Brunhes A, Chevret S, Pons G, Moriette G,

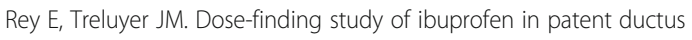
arteriosus using the continual reassessment method. J Clin Pharm Ther. 2005;30(2):121-32 
24. Hirt D, Van Overmeire B, Treluyer JM, Langhendries JP, Marguglio A, Eisinger MJ, Schepens P, Urien S. An optimized ibuprofen dosing scheme for preterm neonates with patent ductus arteriosus, based on a population pharmacokinetic and pharmacodynamic study. Br J Clin Pharmacol. 2008; 65(5):629-36.

25. Dani C, Vangi V, Bertini G, Pratesi S, Lori I, Favelli F, Ciuti R, Bandinelli A, Martano C, Murru P, et al. High-dose ibuprofen for patent ductus arteriosus in extremely preterm infants: a randomized controlled study. Clin Pharmacol Ther. 2012;91(4):590-6.

26. Meissner U, Chakrabarty R, Topf HG, Rascher W, Schroth M. Improved closure of patent ductus arteriosus with high doses of ibuprofen. Pediatr Cardiol. 2012;33(4):586-90.

27. Hammerman C, Bin-Nun A, Markovitch E, Schimmel MS, Kaplan M, Fink D. Ductal closure with paracetamol: a surprising new approach to patent ductus arteriosus treatment. Pediatrics. 2011;128(6):e1618-21.

28. Oncel MY, Yurttutan S, Degirmencioglu H, Uras N, Altug N, Erdeve O, Dilmen $\mathrm{U}$. Intravenous paracetamol treatment in the management of patent ductus arteriosus in extremely low birth weight infants. Neonatology. 2013;103(3):166-9.

29. Dang D, Wang D, Zhang C, Zhou W, Zhou Q, Wu H. Comparison of oral paracetamol versus ibuprofen in premature infants with patent ductus arteriosus: a randomized controlled trial. PLoS One. 2013;8(11):e77888.

30. Oncel MY, Yurttutan S, Uras N, Altug N, Ozdemir R, Ekmen S, Erdeve O, Dilmen $U$. An alternative drug (paracetamol) in the management of patent ductus arteriosus in ibuprofen-resistant or contraindicated preterm infants. Arch Dis Child Fetal Neonatal Ed. 2013;98(1):F94.

31. Sinha R, Negi V, Dalal SS. An interesting observation of PDA closure with oral paracetamol in preterm neonates. Journal of clinical neonatology. 2013; 2(1):30-2.

32. Yurttutan S, Oncel MY, Arayici S, Uras N, Altug N, Erdeve O, Dilmen U. A different first-choice drug in the medical management of patent ductus arteriosus: oral paracetamol. J Matern Fetal Neonatal Med. 2013;26(8):825-7.

33. Kessel I, Waisman D, Lavie-Nevo K, Golzman M, Lorber A, Rotschild A. Paracetamol effectiveness, safety and blood level monitoring during patent ductus arteriosus closure: a case series. J Matern Fetal Neonatal Med. 2014; 27(16):1719-21.

34. Ozdemir OM, Dogan M, Kucuktasci K, Ergin H, Sahin O. Paracetamol therapy for patent ductus arteriosus in premature infants: a chance before surgical ligation. Pediatr Cardiol. 2014;35(2):276-9.

35. Terrin G, Conte F, Scipione A, Bacchio E, Conti MG, Ferro R, Ventriglia F, De Curtis M. Efficacy of paracetamol for the treatment of patent ductus arteriosus in preterm neonates. Ital J Pediatr. 2014;40(1):21.

36. Allegaert K. Paracetamol to close the patent ductus arteriosus: from serendipity toward evidence based medicine. J Postgrad Med. 2013;59(4):251-2.

37. Allegaert K, Anderson B, Simons S, van Overmeire B. Paracetamol to induce ductus arteriosus closure: is it valid? Arch Dis Child. 2013;98(6):462-6.

38. Mazer-Amirshahi M, van den Anker J. Is paracetamol safe and effective for ductus arteriosus closure? Arch Dis Child. 2013;98(10):831

39. Jhaveri N, Moon-Grady A, Clyman Rl: Early surgical ligation versus a conservative approach for management of patent ductus arteriosus that fails to close after indomethacin treatment. The Journal of pediatrics 2010, 157(3):381-387, 387 e381.

40. Wickremasinghe AC, Rogers EE, Piecuch RE, Johnson BC, Golden S, Moon-Grady AJ, Clyman RI. Neurodevelopmental outcomes following two different treatment approaches (early ligation and selective ligation) for patent ductus arteriosus. J Pediatr. 2012;161(6):1065-72.

41. Herrman K, Bose C, Lewis K, Laughon M. Spontaneous closure of the patent ductus arteriosus in very low birth weight infants following discharge from the neonatal unit. Arch Dis Child Fetal Neonatal Ed. 2009;94(1):F48-50.

42. Weber SC, Weiss K, Buhrer C, Hansmann G, Koehne P, Sallmon H. Natural history of patent ductus arteriosus in very low birth weight infants after discharge. J Pediatr. 2015;167(5):1149-51.

43. Alfaleh K, Smyth JA, Roberts RS, Solimano A, Asztalos EV, Schmidt B, Trial of indomethacin prophylaxis in Preterms I: prevention and 18-month outcomes of serious pulmonary hemorrhage in extremely low birth weight infants: results from the trial of indomethacin prophylaxis in preterms. Pediatrics 2008, 121(2):e233-e238.

44. Schmidt B, Davis P, Moddemann D, Ohlsson A, Roberts RS, Saigal S, Solimano A, Vincer M, Wright LL, Trial of indomethacin prophylaxis in Preterms I: long-term effects of indomethacin prophylaxis in extremely-lowbirth-weight infants. N Engl J Med 2001, 344(26):1966-1972.
45. Skelton R, Evans N, Smythe J. A blinded comparison of clinical and echocardiographic evaluation of the preterm infant for patent ductus arteriosus. J Paediatr Child Health. 1994;30(5):406-11.

46. Alagarsamy S, Chhabra M, Gudavalli M, Nadroo AM, Sutija VG, Yugrakh D. Comparison of clinical criteria with echocardiographic findings in diagnosing PDA in preterm infants. J Perinat Med. 2005; 33(2):161-4.

47. McNamara PJ, Sehgal A. Towards rational management of the patent ductus arteriosus: the need for disease staging. Arch Dis Child Fetal Neonatal Ed. 2007;92(6):F424-7.

48. Nemerofsky SL, Parravicini E, Bateman D, Kleinman C, Polin RA, Lorenz JM. The ductus arteriosus rarely requires treatment in infants $>1000$ grams. Am J Perinatol. 2008;25(10):661-6.

49. Koch J, Hensley G, Roy L, Brown S, Ramaciotti C, Rosenfeld CR. Prevalence of spontaneous closure of the ductus arteriosus in neonates at a birth weight of 1000 grams or less. Pediatrics. 2006;117(4):1113-21.

50. Semberova J, Sirc J, Miletin J, Kucera J, Berka I, Sebkova S, O'Sullivan S, Franklin O, Stranak Z. Spontaneous Closure of Patent Ductus Arteriosus in Infants $</=1500$ g. Pediatrics. 2017;140(2):e20164258.

51. Ngo S, Profit J, Gould JB, Lee HC. Trends in patent ductus arteriosus diagnosis and Management for Very low Birth Weight Infants. Pediatrics. 2017;139(4):e20162390

52. Nestrud RM, Hill DE, Arrington RW, Beard AG, Dungan WT, Lau PY, Norton $J B$, Readinger RI. Indomethacin treatment in patent ductus arteriosus. A double-blind study utilizing indomethacin plasma levels. Dev Pharmacol Ther. 1980;1(2-3):125-36.

53. Merritt TA, Harris JP, Roghmann K, Wood B, Campanella V, Alexson C, Manning J, Shapiro DL. Early closure of the patent ductus arteriosus in very low-birth-weight infants: a controlled trial. J Pediatr. 1981;99(2):281-6.

54. Yanagi RM, Wilson A, Newfeld EA, Aziz KU, Hunt CE. Indomethacin treatment for symptomatic patent ductus arteriosus: a double-blind control study. Pediatrics. 1981;67(5):647-52.

55. Yeh TF, Luken JA, Thalji A, Raval D, Carr I, Pildes RS. Intravenous indomethacin therapy in premature infants with persistent ductus arteriosus--a double-blind controlled study. J Pediatr. 1981;98(1):137-45.

56. Mahony L, Caldwell RL, Girod DA, Hurwitz RA, Jansen RD, Lemons JA, Schreiner RL. Indomethacin therapy on the first day of life in infants with very low birth weight. J Pediatr. 1985;106(5):801-5.

57. Mahony L, Carnero V, Brett C, Heymann MA, Clyman RI. Prophylactic indomethacin therapy for patent ductus arteriosus in very-low-birth-weight infants. N Engl J Med. 1982;306(9):506-10.

58. Mullett MD, Croghan TW, Myerberg DZ, Krall JM, Neal WA. Indomethacin for closure of patent ductus arteriosus in prematures. Clin Pediatr. 1982;21(4):217-20.

59. Gersony WM, Peckham GJ, Ellison RC, Miettinen OS, Nadas AS. Effects of indomethacin in premature infants with patent ductus arteriosus: results of a national collaborative study. J Pediatr. 1983;102(6):895-906.

60. Kaapa P, Lanning P, Koivisto M. Early closure of patent ductus arteriosus with indomethacin in preterm infants with idiopathic respiratory distress syndrome. Acta Paediatr Scand. 1983;72(2):179-84.

61. Monset-Couchard M, Dias-Mancano D, Murat I, Relier JP. Controlled trial of intravenous lyophilized indomethacin in the treatment of persistent ductus arteriosus in premature infants. Pediatrie. 1983;38(6):365-77.

62. Rudd P, Montanez $\mathrm{P}$, Hallidie-Smith $\mathrm{K}$, Silverman M. Indomethacin treatment for patent ductus arteriosus in very low birthweight infants: double blind trial. Arch Dis Child. 1983;58(4):267-70.

63. Hammerman C, Strates E, Komar K, Bui K. Failure of prophylactic indomethacin to improve the outcome of the very low birth weight infant. Dev Pharmacol Ther. 1987;10(6):393-404.

64. Hammerman C, Strates E, Valaitis S. The silent ductus - its precursors and its aftermath. Pediatr Cardiol. 1986;7(3):121-7.

65. Rennie JM, Doyle J, Cooke RWI. Early Administration of Indomethacin to preterm infants. Arch Dis Child. 1986;61(3):233-8.

66. Krueger E, Mellander M, Bratton D, Cotton R. Prevention of symptomatic patent ductus-arteriosus with a single dose of indomethacin. J Pediatr-Us. 1987;111(5):749-54.

67. Vincer M, Allen A, Evans J, Nwaesei C, Stinson D, Rees E, Fraser A. Early intravenous indomethacin prolongs respiratory support in very-low-birthweight infants. Acta Paediatr Scand. 1987;76(6):894-7.

68. Weesner KM, Dillard RG, Boyle RJ, Block SM. Prophylactic treatment of asymptomatic patent ductus-arteriosus in premature-infants with respiratory-distress syndrome. Southern Med J. 1987;80(6):706-8. 
69. Vogtmann C, Grubbe G, Ruckhaberle KE, Bottcher H, Ockert C. The effects of an early indomethacin treatment on the manifestation of a patent ductus-arteriosus in very low birth-weight infants. Monatsschr Kinderh. 1988;136(9):636-9.

70. Couser RJ, Ferrara TB, Wright GB, Cabalka AK, Schilling CG, Hoekstra RE, Payne NR. Prophylactic indomethacin therapy in the first twenty-four hours of life for the prevention of patent ductus arteriosus in preterm infants treated prophylactically with surfactant in the delivery room. J Pediatr. 1996; 128(5 Pt 1):631-7.

71. Supapannachart S, Khowsathit P, Patchakapati B. Indomethacin prophylaxis for patent ductus arteriosus (PDA) in infants with a birth weight of less than 1250 grams. J Med Assoc Thail. 1999;82(Suppl 1):S87-92.

72. De Carolis MP, Romagnoli C, Polimeni V, Piersigilli F, Zecca E, Papacci P, Delogu AB, Tortorolo G. Prophylactic ibuprofen therapy of patent ductus arteriosus in preterm infants. Eur J Pediatr. 2000;159(5):364-8.

73. Osborn DA, Evans N, Kluckow M. Effect of early targeted indomethacin on the ductus arteriosus and blood flow to the upper body and brain in the preterm infant. Arch Dis Child Fetal Neonatal Ed. 2003;88(6):F477-82.

74. Gournay V, Roze JC, Kuster A, Daoud P, Cambonie G, Hascoet JM, Chamboux C, Blanc T, Fichtner C, Savagner C, et al. Prophylactic ibuprofen versus placebo in very premature infants: a randomised, double-blind, placebo-controlled trial. Lancet. 2004;364(9449):1939-44.

75. Van Overmeire B, Allegaert K, Casaer A, Debauche C, Decaluwe W, Jespers A, Weyler J, Harrewijn I, Langhendries JP. Prophylactic ibuprofen in premature infants: a multicentre, randomised, double-blind, placebocontrolled trial. Lancet. 2004;364(9449):1945-9.

76. Sangtawesin C, Sangtawesin V, Lertsutthiwong W, Kanjanapattanakul W Khorana M, Ayudhaya JK. Prophylaxis of symptomatic patent ductus arteriosus with oral ibuprofen in very low birth weight infants. J Med Assoc Thail. 2008;91(Suppl 3):S28-34.

77. Sangtawesin V, Sangtawesin C, Raksasinborisut C, Sathirakul K, Kanjanapattanakul W, Khorana M, Horpaopan S. Oral ibuprofen prophylaxis for symptomatic patent ductus arteriosus of prematurity. J Med Assoc Thail. 2006;89(3):314-21.

78. Aranda JV, Clyman R, Cox B, Van Overmeire B, Wozniak P, Sosenko I, Carlo WA, Ward RM, Shalwitz R, Baggs G, et al. A randomized, double-blind, placebo-controlled trial on intravenous ibuprofen L-lysine for the early closure of nonsymptomatic patent ductus arteriosus within 72 hours of birth in extremely low-birth-weight infants. Am J Perinatol. 2009;26(3):235-45.

79. Maruyama K, Fujiu T. Effects of prophylactic indomethacin on renal and intestinal blood flows in premature infants. Pediatrics international : official journal of the Japan Pediatric Society. 2012;54(4):480-5.

80. Kanmaz G, Erdeve O, Canpolat FE, Oguz SS, Uras N, Altug N, Greijdanus B, Dilmen U. Serum ibuprofen levels of extremely preterm infants treated prophylactically with oral ibuprofen to prevent patent ductus arteriosus. Eur J Clin Pharmacol. 2013;69(5):1075-81.

81. Letshwiti JB, Semberova J, Pichova K, Dempsey EM, Franklin OM, Miletin J. A conservative treatment of patent ductus arteriosus in very low birth weight infants. Early Hum Dev. 2017;104:45-9.

82. Lokku A, Mirea L, Lee SK, Shah PS, Canadian Neonatal N. Trends and outcomes of patent ductus arteriosus treatment in very preterm infants in Canada. Am J Perinatol. 2017;34(5):441-50.

83. Rolland A, Shankar-Aguilera S, Diomande D, Zupan-Simunek V, Boileau P. Natural evolution of patent ductus arteriosus in the extremely preterm infant. Arch Dis Child Fetal Neonatal Ed. 2015;100(1):F55-8.

84. Slaughter JL, Reagan PB, Newman TB, Klebanoff MA. Comparative effectiveness of nonsteroidal anti-inflammatory drug treatment vs no treatment for patent ductus arteriosus in preterm infants. JAMA Pediatr. 2017;171(3):e164354

85. Sung SI, Chang YS, Chun JY, Yoon SA, Yoo HS, Ahn SY, Park WS. Mandatory closure versus nonintervention for patent ductus arteriosus in very preterm infants. J Pediatr. 2016;177:66-71. e61

86. Vanhaesebrouck S, Zonnenberg I, Vandervoort P, Bruneel E, Van Hoestenberghe MR, Theyskens C. Conservative treatment for patent ductus arteriosus in the preterm. Arch Dis Child Fetal Neonatal Ed. 2007;92(4):F244-7.

87. Mohamed MA, El-Dib M, Alqahtani S, Alyami K, Ibrahim AN, Aly H. Patent ductus arteriosus in premature infants: to treat or not to treat? J Perinatol: official journal of the California Perinatal Association. 2017;

88. Mirea L, Sankaran K, Seshia M, Ohlsson A, Allen AC, Aziz K, Lee SK, Shah PS, Canadian Neonatal N. Treatment of patent ductus arteriosus and neonatal mortality/morbidities: adjustment for treatment selection bias. J Pediatr. 2012;161(4):689-94. e681
89. Sadeck LSR, Leone CR, Procianoy RS, Guinsburg R, Marba STM, Martinez FE, Rugolo LMSS, Moreira MEL, Fiori RM, Ferrari LL, et al. Effects of therapeutic approach on the neonatal evolution of very low birth weight infants with patent ductus arteriosus. J Pediatr. 2014;90(6):616-23.

90. Horbar JD, Carpenter JH, Badger GJ, Kenny MJ, Soll RF, Morrow KA, Buzas JS Mortality and neonatal morbidity among infants 501 to 1500 grams from 2000 to 2009. Pediatrics. 2012;129(6):1019-26.

91. Liebowitz M, Clyman RI. Prophylactic indomethacin compared with delayed conservative Management of the Patent Ductus Arteriosus in extremely preterm infants: effects on neonatal outcomes. J Pediatr. 2017;

92. Chock VY, Goel W, Palma JP, Luh TM, Wang NA, Gaskari S, Punn R, Silverman NH, Benitz WE. Changing Management of the Patent Ductus Arteriosus: effect on neonatal outcomes and resource utilization. Am J Perinatol. 2017;

93. Kaempf JW, Wu YX, Kaempf AJ, Kaempf AM, Wang L, Grunkemeier G. What happens when the patent ductus arteriosus is treated less aggressively in very low birth weight infants? J Perinatol: official journal of the California Perinatal Association. 2012;32(5):344-8.

94. Madan JC, Kendrick D, Hagadorn JI, Frantz ID, 3rd, National Institute of child $\mathrm{H}$, human development neonatal research $\mathrm{N}$ : Patent ductus arteriosus therapy: impact on neonatal and 18-month outcome. Pediatrics 2009, 123(2):674-681.

95. Sathiyamurthy S, Thomson M, Tyszczuk L, Groves A. Non-treatment of patent ductus arteriosus and short term outcomes in extremely low birth weight infants (Elbw). Pediatr Res. 2011;70:273.

96. Groves AM, Kuschel CA, Knight DB, Skinner JR. Cardiorespiratory stability during echocardiography in preterm infants. Arch Dis Child. 2005;90(1):86-7.

97. Noori S, Seri I. Does targeted neonatal echocardiography affect hemodynamics and cerebral oxygenation in extremely preterm infants? J Perinatol: official journal of the California Perinatal Association. 2014;34(11):847-9.

98. Kluckow M, Evans N. Early echocardiographic prediction of symptomatic patent ductus arteriosus in preterm infants undergoing mechanical ventilation. J Pediatr. 1995;127(5):774-9.

99. Neu J. Necrotizing enterocolitis: the search for a unifying pathogenic theory leading to prevention. Pediatr Clin N Am. 1996;43(2):409-32.

100. Bancalari E, Claure N. Definitions and diagnostic criteria for bronchopulmonary dysplasia. Semin Perinatol. 2006;30(4):164-70.

101. Walsh MC, Yao Q, Gettner P, Hale E, Collins M, Hensman A, Everette R, Peters N, Miller N, Muran G, et al. Impact of a physiologic definition on bronchopulmonary dysplasia rates. Pediatrics. 2004;114(5):1305-11.

102. Volpe JJ. Neurology of the newborn, 5th ed. edn. Philadelphia, pa. London: Saunders; 2008.

103. Hashimoto K, Hasegawa H, Kida Y, Takeuchi Y. Correlation between neuroimaging and neurological outcome in periventricular leukomalacia: diagnostic criteria. Pediatrics international : official journal of the Japan Pediatric Society. 2001;43(3):240-5.

104. International Committee for the Classification of Retinopathy of Prematurity. The international classification of retinopathy of prematurity revisited. Arch Ophthalmol. 2005;123(7):991-9.

105. Hakkaart-van Roijen L, Tan SS, Bouwmans CAM: Handleiding voor kostenonderzoek: Methoden en standaard kostprijzen voor economische evaluaties in de gezondheidszorg. . In., Third edn: Diemen: College voor zorgverzekeringen 2010.

106. Bouwmans C, Krol M, Brouwer W, Severens JL, Koopmanschap MA, Hakkaart L. Imta Productivity Cost Questionnaire (Ipcq). Value Health. 2014;17(7):A550

107. Sullivan SD, Mauskopf JA, Augustovski F, Jaime Caro J, Lee KM, Minchin M, Orlewska E, Penna P, Rodriguez Barrios JM, Shau WY. Budget impact analysisprinciples of good practice: report of the ISPOR 2012 budget impact analysis good practice II task force. Value in health : the journal of the International Society for Pharmacoeconomics and Outcomes Research. 2014;17(1):5-14.

108. Garattini L, van de Vooren K. Budget impact analysis in economic evaluation: a proposal for a clearer definition. The European journal of health economics : HEPAC : health economics in prevention and care. 2011 . 12(6):499-502.

109. Malcolm DD, Segar JL, Robillard JE, Chemtob S. Indomethacin compromises hemodynamics during positive-pressure ventilation, independently of prostanoids. J Appl Physiol. 1993;74(4):1672-8.

110. Pezzati M, Vangi V, Biagiotti R, Bertini G, Cianciulli D, Rubaltelli FF. Effects of indomethacin and ibuprofen on mesenteric and renal blood flow in preterm infants with patent ductus arteriosus. J Pediatr. 1999;135(6):733-8. 
111. Speziale MV, Allen RG, Henderson CR, Barrington KJ, Finer NN. Effects of ibuprofen and indomethacin on the regional circulation in newborn piglets. Biol Neonate. 1999;76(4):242-52.

112. Chemtob S, Laudignon N, Beharry K, Rex J, Varma D, Wolfe L, Aranda JV. Effects of prostaglandins and indomethacin on cerebral blood flow and cerebral oxygen consumption of conscious newborn piglets. Dev Pharmacol Ther. 1990;14(1):1-14.

113. Mosca F, Bray M, Lattanzio M, Fumagalli M, Tosetto C. Comparative evaluation of the effects of indomethacin and ibuprofen on cerebra perfusion and oxygenation in preterm infants with patent ductus arteriosus. J Pediatr. 1997;131(4):549-54.

114. Patel J, Roberts I, Azzopardi D, Hamilton P, Edwards AD. Randomized double-blind controlled trial comparing the effects of ibuprofen with indomethacin on cerebral hemodynamics in preterm infants with patent ductus arteriosus. Pediatr Res. 2000:47(1):36-42.

115. Gokmen T, Erdeve O, Altug N, Oguz SS, Uras N, Dilmen U. Efficacy and safety of oral versus intravenous ibuprofen in very low birth weight preterm infants with patent ductus arteriosus. J Pediatr. 2011;158(4):549-54. e541

116. Neumann R, Schulzke SM, Buhrer C. Oral ibuprofen versus intravenous ibuprofen or intravenous indomethacin for the treatment of patent ductus arteriosus in preterm infants: a systematic review and meta-analysis. Neonatology. 2012;102(1):9-15.

117. Olukman O, Calkavur S, Ercan G, Atlihan F, Oner T, Tavli V, Kultursay N. Comparison of oral and intravenous ibuprofen for medical closure of patent ductus arteriosus: which one is better? Congenit Heart Dis. 2012;7(6):534-43.

118. Eras Z, Gokmen T, Erdeve O, Ozyurt BM, Saridas B, Dilmen U. Impact of oral versus intravenous ibuprofen on neurodevelopmental outcome: a randomized controlled parallel study. Am J Perinatol. 2013;30(10):857-62.

119. Annual reports [https://www.perined.nl/producten/publicaties/jaarboeken], Accessed 27 February 2018.

120. Cook D, Lauzier F, Rocha MG, Sayles MJ, Finfer S. Serious adverse events in academic critical care research. CMAJ : Canadian Medical Association journal = journal de l'Association medicale canadienne. 2008;178(9):1181-4.

121. Cook D, Moore-Cox A, Xavier D, Lauzier F, Roberts I. Randomized trials in vulnerable populations. Clinical trials. 2008:5(1):61-9.

122. Standard research file [http://www.ccmo.nl/en/standard-research-file], Accessed 27 February 2018

Ready to submit your research? Choose BMC and benefit from:

- fast, convenient online submission

- thorough peer review by experienced researchers in your field

- rapid publication on acceptance

- support for research data, including large and complex data types

- gold Open Access which fosters wider collaboration and increased citations

- maximum visibility for your research: over $100 \mathrm{M}$ website views per year

At $\mathrm{BMC}$, research is always in progress.

Learn more biomedcentral.com/submissions 